\title{
Corrigendum: Something about the Balancing of Thermal Motors
} \author{
${ }^{6}$ Guanying Chen, ${ }^{7}$ Shuhui Li, ${ }^{1}$ Antonio Apicella and ${ }^{2}$ Florian Ion T. Petrescu \\ ${ }^{I}$ Advanced Material Lab, Department of Architecture and Industrial Design, \\ Second University of Naples, 81031 Aversa (CE), Italy \\ ${ }^{2}$ ARoTMM-IFToMM, Bucharest Polytechnic University, Bucharest, (CE), Romania \\ ${ }^{3}$ Dean of School of Graduate Studies and Research, American University of Ras Al Khaimah, UAE \\ ${ }^{4}$ Union College, USA \\ ${ }^{5}$ University of Salamanca, Spain \\ ${ }^{6}$ Harbin Institute of Technology and SUNY Buffalo, China \\ ${ }^{7}$ University of Alabama, USA
}

${ }^{1}$ Raffaella Aversa, ${ }^{2}$ Relly Victoria V. Petrescu, ${ }^{3}$ Bilal Akash, ${ }^{4}$ Ronald B. Bucinell, ${ }^{5}$ Juan M. Corchado,

Correction to: American Journal of Engineering and Applied Sciences http://doi.org/10.3844/ajeassp.2017.200.217, published online 15 March 2017; updated 29 August 2019

The original version of this Article contained Mr. MirMilad Mirsayar as a CoAuthor. Mr. Mirsayar has not contributed to the preparation and publication of this manuscript.

These errors have now been corrected in the HTML and PDF versions of the Article. http://doi.org/10.3844/ajeassp.2017.200.217. 